\title{
choer
}

\section{Direito e resistência: grupos de assessoria jurídica universitária popular no Ceará}

\section{Livia Maria Nascimento Silva}

Graduanda em Direito na Universidade Regional do Cariri - URCA

liviamarians1@gmail.com

\author{
Amanda Oliveira de Sousa \\ Graduanda em Direito na Universidade Regional do Cariri - URCA \\ oliveiraamanda482@gmail.com
}

\section{Djamiro Ferreira Acipreste Sobrinho}

Doutor em Sociedade Democrática, Estado e Direito - Universidade do País Basco

Professor do Departamento de Direito - URCA

djamiro.acipreste@urca.br

\section{Resumo}

\begin{abstract}
A assessoria jurídica universitária popular (AJUP) é um movimento de extensão universitária que atua junto às minorias sociais, como espaço alternativo diante do positivismo dogmático majoritário. Em tal cenário, este artigo tem por objetivo apresentar as AJUPs do Estado do Ceará, suas áreas de atuação, seus obstáculos e suas perspectivas, ressaltando os aspectos pedagógicos construtores da militância em direito. Para tanto, 3 etapas foram percorridas: a) localização dos grupos; b) aplicação de questionários; e c) participação em reuniões. Constatouse que os 6 grupos identificados atuam em áreas diversificadas, mas eles têm em comum o método de execução da educação popular em direitos humanos e sua proximidade com os movimentos sociais. Dessa forma, as AJUPs surgem como possibilidade de ressignificação da educação jurídica, projetando uma prática mais humanizada e engajada em causas sociais.
\end{abstract}

Palavras-chave educação jurídica; extensão universitária; direito alternativo; educação popular em direitos humanos; essessoria jurídica universitária popular.

\footnotetext{
Conhecer: debate entre o público e o privado 2019, Vol. 09, no 22

ISSN 2238-0426

DOI 10.32335/2238-0426.2019.9.22.1033

Licença Creative Commons Atribuição (CC BY 4.0)

Data de submissão 10 fev 19

Data de publicação 22 abr 19
} 


\title{
Law and resistance: popular university legal advisory groups in Ceará
}

\begin{abstract}
opular university legal advice (assessoria jurídica universitária popular - AJUP) is a university outreach movement that works along with social minorities, as an alternative space in the face of mainstream dogmatic positivism. In such a scenario, this article aims to introduce the popular university legal advisory groups (AJUPs) in the State of Ceará, their areas of action, their obstacles, and their perspectives, highlighting the pedagogical aspects that build legal activism. To do this, 3 stages were covered: a) identification of groups; b) application of questionnaires; and c) participation in meetings. It was found that the 6 groups identified operate in a number of areas, but they have in common the method of providing popular education in human rights and their closeness to social movements. Thus, the AJUPs emerge as a possibility to re-signify legal education, by designing a practice more humanized and engaged in social causes.
\end{abstract}

Key words legal education; university outreach; alternative law; popular education in human rights; popular university legal advice.

\section{Derecho y resistencia: grupos de asesoría jurídica universitaria popular en Ceará}

\section{Resumen}

La asesoría jurídica universitaria popular (assessoria jurídica universitária popular - AJUP) es un movimiento de extensión universitaria que actúa junto con las minorías sociales, como un espacio alternativo frente al positivismo dogmático mayoritario. En tal escenario, este artículo tiene como objetivo presentar los grupos de asesoría jurídica universitaria popular (AJUPs) en el Estado de Ceará, sus áreas de actuación, sus obstáculos y sus perspectivas, destacando los aspectos pedagógicos constructores de la militancia en derecho. Para ello, se cubrieron 3 etapas: a) identificación de grupos; b) aplicación de cuestionarios; y c) participación en reuniones. Se constató que los 6 grupos identificados actúan en varias áreas, pero tienen en común el método de ejecución de la educación popular en materia de derechos humanos y su cercanía a los movimientos sociales. De esta forma, los AJUPs emergen como una posibilidad de resignificación de la educación jurídica, proyectando una práctica más humanizada y comprometida con causas sociales.

Palabras clave educación jurídica; extensión universitaria; derecho alternativo; educación popular en derechos humanos; asesoría jurídica universitaria popular. 


\section{Introdução}

A assessoria jurídica universitária popular (AJUP) é uma vertente de extensão universitária, com raízes no direito alternativo, que se apresenta como perspectiva metodológica voltada ao "popular". Em sua essência, encarna o desenvolvimento de atividades integradoras entre a universidade e a sociedade, norteadas pela educação popular como instrumentalizadoras do debate sobre direitos humanos e, também, do empoderamento de sujeitos historicamente marginalizados.

Apesar do termo assessoria designar que esses grupos atuam com o povo e para o povo, geralmente é usado como sinônimo de assistência. Tradicionalmente, no âmbito jurídico do Brasil, a assistência judiciária é conhecida por ser o meio de conferir efetividade ao princípio que garante à população hipossuficiente acesso gratuito e integral à Justiça, o qual é assegurado pela Constituição da República Federativa do Brasil (CF, 1988).

Esse modelo assistencial é ofertado tradicionalmente pela Defensoria Pública, instituição essencial à função jurisdicional do Estado, que tem por ofício defender os direitos humanos e os interesses individuais e coletivos da população hipossuficiente, judicial ou extrajudicialmente.

Entretanto, mesmo reconhecendo a importância desse equipamento de promoção e defesa dos direitos das pessoas que mais necessitam, deve-se ressaltar que, cada vez mais, mostra-se necessário um instrumento que, além de defender as classes sociais menos favorecidas, possibilite o empoderamento desses segmentos, bem como sua formação a partir de uma consciência crítica e participação na busca de uma sociedade mais justa e igualitária.

Nesse contexto, aponta-se a prática da AJUP como movimento que proporciona uma concepção alternativa para efetivar os direitos na busca por justiça social, que propõe a dinamicidade na prática jurídica, trazendo à tona questões sociais, políticas e culturais diante do formalismo e positivismo jurídico, de modo a aperfeiçoar a concepção do bacharel em Direito, além de executar um trabalho formativo junto à sociedade, a fim de tornar os sujeitos capazes, autônomos e protagonistas de uma transformação social.

Por isso, o termo assessoria se mostra o mais adequado para classificar a AJUP e sua metodologia, pois esta representa uma prática inovadora e criativa de construir o direito. Os assessores populares enxergam nesse termo uma definição política oposta às propostas da assistência. A ação política da assessoria tem por finalidade promover a formação do cidadão - por meio da educação popular em direitos humanos -, sua mobilização e sua organização na coletividade para que possa compreender e atuar na cobrança de seus direitos.

Nesse sentido, é no marco teórico de Paulo Freire, em sua metodologia da educação popular, que as AJUPs encontram sua base, com atividade jurídica e na própria extensão 
universitária de maneira dialógica e horizontal, reconhecendo nos sujeitos com quem atuam que estes podem integrar um novo modelo de sociedade, pautando a luta pela efetivação dos direitos e garantias previstos na legislação, bem como a quebra do modelo de exclusão social ao qual estão submetidos. Não se trata de tarefa fácil, porém, isso não é impossível.

A partir de tal conjuntura, este artigo tem por objetivo apresentar os grupos de AJUP do Ceará e suas contribuições na formação crítica e política no meio acadêmico e popular, enxergando neles a possibilidade de construção de espaços democráticos e horizontais no âmbito do direito. Os dados apresentados são os resultados finais do projeto de pesquisa "Importância da assessoria jurídica universitária popular no ensino jurídico brasileiro: um levantamento da atuação das AJUPs no Estado do Ceará", desenvolvido entre fevereiro e dezembro de 2018, com apoio do Programa Institucional de Bolsas de Iniciação Científica da Universidade Regional do Cariri (PIBIC/URCA) aprovado pelo Edital n. 06/2017.

\section{Metodologia}

Com duração de um ano, esta pesquisa consistiu em estudo exploratório e descritivo, com abordagem quantiqualitativa, realizado a partir do levantamento da atuação de 6 grupos de AJUP no Ceará.

Inicialmente, procedeu-se a um levantamento dos grupos que integram a Rede Nacional de Assessoria Jurídica Universitária (RENAJU), organização que congrega diversas AJUPs do Brasil. No site da RENAJU há um mapeamento de todos os grupos que a integram, contendo nome e instituição à qual cada um se vincula. Após essa identificação, realizou-se contato prévio por meio da rede social Facebook e do e-mail de cada grupo, explicando o estudo e convidando-o a participar da pesquisa.

A coleta de dados foi realizada a partir de 2 técnicas: a) participação nas atividades de articulação conjunta entre os grupos (reuniões on-line); e b) aplicação de 2 questionários semiestruturados, a saber: i) um questionário para caracterização do grupo; e ii) outro para caracterização de seus integrantes, que o responderam de forma livre e consentida após o aceite em participar da pesquisa.

Os 2 questionários foram enviados via Google Forms aos membros de cada AJUP. Dos 6 grupos de AJUP identificados no Ceará, 5 responderam o questionário - 1 deles foi desativado em maio de 2018. Em relação aos seus respectivos membros, nem todos participaram, por isso, a identificação do perfil dos participantes se refere apenas às 30 pessoas que responderam - dos 5 grupos ativos à época da pesquisa.

\section{Breves considerações sobre o curso de direito no Brasil}

No Brasil, a tradição do ensino jurídico tem em suas raízes um forte positivismo dogmático, majoritariamente legalista, herança dos cursos superiores da Europa, posto que, 
a princípio, os bacharéis que atuavam no país eram oriundos da Universidade de Coimbra (Portugal). Isso evidencia que o curso foi voltado, a priori, às elites de nossa sociedade, que tinham condições socioeconômicas de seguir uma trajetória acadêmica fora do país.

Apenas entre 1808 e 1810 foram criados os primeiros cursos superiores médicocirúrgicos nas capitais do Brasil (Rio de Janeiro-RJ e Salvador-BA). Depois veio o primeiro curso de Engenharia, em seguida o de Ciências Econômicas e os cursos de Artes Visuais surgiram em 1820. Somente em 1827 foram instalados os 2 primeiros cursos jurídicos: um em Olinda-PE, posteriormente transferido para Recife-PE; e outro em São Paulo-SP. Luiz Antonio Bove (2006, p. 120) afirma que:

[...] de forma oblíqua, foi compelido que fossem criados cursos superiores com pouco critério educacional para atender os anseios imediatos dos filhos da aristocracia colonial dominante. Com isso, o sistema de Ensino Superior sofreu, já de início, de forma significante, a interferência marcante dessas faculdades, pouco universitárias mas, na essência, com notada coloração política governante da época.

O autor acrescenta que, depois de 1950, houve grande aumento do número de matrículas no Ensino Superior, devido ao desenvolvimento tecnológico do país, que exigia melhor qualificação da mão de obra, induzindo a abertura de novas faculdades federais, estaduais e municipais. Contudo, o governo, assumindo não ser capaz de atender à demanda, facilitou a iniciativa privada no âmbito educacional. Dessa forma, a qualidade do ensino foi caindo, já que tudo foi criado às pressas, sem planejamento e sem organização.

A discussão acerca da crise do ensino jurídico não é recente, posto que a própria implantação dos cursos de Direito no Brasil, em 1827, já demonstra uma falha, pois seu objetivo inicial era qualificar as elites para a manutenção do poder político, econômico e administrativo do país. Ser bacharel em Direito era status da burguesia, fenômeno denominado bacharelismo (Andrade, 2009). Segundo Linhares (2009), por vezes, as propostas de revisão curricular da Graduação em Direito foi pauta de debate. Contudo, apesar das modificações já instituídas com o intuito de melhorar o curso, as raízes da dogmática positivista ainda estão presentes.

Nesse contexto, compreender a distinção entre o ensino e a educação se mostra fundamental para analisar qual é o papel da AJUP na busca por (trans)formação da educação jurídica. A educação tem como foco principal o "desenvolvimento integral das potencialidades da pessoa humana" (Fagúndez, 1997), enquanto o ensino se restringe à relação ensino-aprendizagem e a instrução busca apenas um treinamento do indivíduo, de forma ainda mais restrita. 
Assim, o caráter restrito e limitado dos cursos superiores, a princípio, acabou distanciando a classe popular do meio universitário, bem como dos assuntos a ele relacionados, consolidando um espaço de instrução, no máximo de ensino. Entretanto, para compreender melhor o direito, faz-se necessário entender as dimensões sociais, culturais, históricas e políticas que circundam as Ciências Sociais, pois o Direito é um fator humano e, portanto, a educação deve ser construída humanisticamente nesse âmbito.

Em virtude desses aspectos, pode-se compreender que a universidade deve alicerçar sua prática pedagógica em uma macrovisão, estabelecendo uma relação causal entre realidade e teoria, com base em todas as dimensões possíveis para construir ideias integralizadas. Por isso, não se pode limitar a educação à sala de aula, ao formalismo, à mera domesticação do homem por meio da instrução - como vê Paulo Freire (2005) ao tratar da educação bancária.

\section{Da crise do direito ao despertar: experiências de assessoria jurídica universitária popular}

Compreendidas as problemáticas da construção do ensino jurídico, nota-se que as propostas alternativas de educação e prática jurídica são, de fato, ideias que resistem na disputa por uma epistemologia jurídica que se abra ao pluralismo de ideias, à diversidade e à mudança do paradigma imposto pelo tecnicismo acadêmico dos cursos de Direito. Nesse sentido, Ana Lia Vanderlei de Almeida (2015) aponta as AJUPs como os "estalos" que as faculdades de Direito careciam para sua mudança.

Nesse delinear, para que se possa compreender melhor a proposta oferecida por esses grupos, delimita-se, inicialmente, o conceito e significado real da assessoria jurídica popular (AJP):

\footnotetext{
A AJUP é parte da noção mais ampla de "Assessoria Jurídica Popular" (AJP), relacionada a práticas de sujeitos do campo jurídico que se colocam ao lado dos trabalhadores e dos demais sujeitos subalternizados em seus enfrentamentos na sociedade de classes. A "assessoria jurídica popular" pode ser entendida como gênero que comporta dois campos principais: o da advocacia popular congregando advogadas e advogados; e o da assessoria jurídica universitária popular, formado por grupos ligados às universidades (geralmente localizados no âmbito da extensão), protagonizados por estudantes e/ou professores, principalmente do Direito, mas também de outras áreas [...] (Almeida, 2015, p. 48, grifo da autora).
} 
O fato condutor dessa forma diferenciada de compreender e atuar na área jurídica, junto às camadas mais espoliadas da sociedade, nasceu de demandas sociais no contexto político e ideológico pós-ditatorial. Inclusive, houve um forte movimento de advogados populares contra a ditadura, que atuou na defesa e proteção dos direitos dos perseguidos e presos políticos durante o regime militar. Antônio Alberto Machado (2009, p. 1) afirma que o direito alternativo é um movimento "político/jurídico e prático/teórico, deflagrado no final da década dos anos 60 por juízes integrantes da chamada Magistratura Democrática da Itália, difundindo-se em seguida pela Espanha até chegar à América Latina”.

Esse movimento foi articulado, a princípio, por professores e demais profissionais do direito, que passaram a enxergá-lo como um instrumento favorável de mudança social, de solidificação da democracia e de construção de uma sociedade justa.

\footnotetext{
Tal vertente do pensamento jurídico, importante frisar desde logo, propõe mesmo uma franca ruptura com o modelo jurídico liberal/positivista, que estrutura o direito burguês e mantém o esquema de dominação na sociedade capitalista, buscando novos paradigmas para a ciência e para a práxis jurídicas, a partir de uma compreensão dialética do fenômeno jurídico que anuncia um novo modelo de sociedade, muito provavelmente de tipo socialista (Machado, 2009, p. 1).
}

No mesmo sentido, Lédio Rosa de Andrade (1996, p. 5, grifo do autor), um dos juristas mais reconhecidos por seu estudo sobre direito alternativo, aponta que este:

\begin{abstract}
Pretende ser mais uma forma de luta existente e posta à disposição daqueles desejos de permanecer digladiando-se contra a violência, a exploração, a miséria e todas as demais formas desabonadoras da pessoa humana. Em um país onde o Estado e as instituições jurídicas mais servem para regredir as conquistas históricas, permitindo e ampliando as desigualdades sociais, a exploração desenfreada e a escravidão fática das camadas populares, do que para possibilitar igualdades e liberdades, iniciou esse movimento, dentro do âmbito jurídico, não com o propósito de criar uma sociedade ideal, mas, sim, de possibilitar a transformação da Ciência do Direito em mais um meio de liça, na defesa do que se costuma chamar as grandes conquistas da humanidade.
\end{abstract}

É importante ressaltar que essa concepção de direito estampa uma crítica ferrenha, sempre partindo do questionamento de como e para quem o direito serve. Identifica-se certo esgotamento do paradigma positivo-normativo da área jurídica, que nada mais é do que mero reflexo do sistema capitalista, que sujeitou as pessoas a um cenário de injustiça 
e exclusão. Paulo Roney Ávila Fagúndez (1997) aponta em seus estudos a crise que assola o direito, que parte desde a formação do bacharel:

\footnotetext{
Há necessidade de serem analisadas as grandes crises que afetam o ensino jurídico. [...] Diz que a crise funcional desdobra-se em crise do mercado de trabalho e em crise de identidade e legitimidade dos operadores jurídicos. Por sua vez, a crise operacional se subdivide em crise curricular, crise didático-pedagógica e crise administrativa. A terceira grande crise [...] é estrutural e apresenta, em essência, duas vertentes: a crise do paradigma político-ideológico e a crise do paradigma epistemológico. Não [se] deve deixar de levar em consideração que a moderna racionalidade organizou o modelo de ensino que impera até hoje em dia.
}

Diante dessa crise operacional e sistemática, percebe-se a imperatividade de qualquer acadêmico ter uma formação baseada, de fato, no tripé pedagógico ensino, pesquisa e extensão - que sustenta a universidade. Daí decorre a importância e necessidade dos estudantes questionarem e adotarem uma visão crítica do direito, além de perceberem e engajarem-se em lutas sociais.

Apenas os códigos não bastam para uma formação profissional e cidadã do estudante de Direito. Assim, urge a necessidade de buscar novos marcos teóricos na ciência jurídica, que abram espaço para novos meios de resolução de conflitos, para o pluralismo e o debate de ideias, além da interdisciplinaridade, buscando transformar, e não mais conservar, essa realidade social engessada, reprodutora de preconceitos, marginalização e criminalização de indivíduos e grupos específicos.

Os núcleos de AJUP nasceram no Brasil com vistas a preencher essa lacuna no ensino jurídico, com uma proposta de educação diferenciada. O primeiro grupo de AJUP surgiu em meados de 1950, na Universidade Federal do Rio Grande do Sul (UFRGS), e o segundo em 1963, na Universidade Federal da Bahia (UFBA), nas quais os acadêmicos e professores de Direito almejavam praticar junto à população tudo que aprendiam na teoria (Almeida, 2015).

Contudo, o entendimento da essencialidade da construção da assessoria com e para o povo ainda não estava consolidado a princípio. Foi apenas com o fortalecimento e a união dos movimentos pela defesa e proteção dos direitos humanos e da justiça no contexto da ditadura militar no Brasil que surgiram mais grupos de AJUP com base teórica pautada na crítica ao direito, no direito alternativo e na educação popular de Paulo Freire. Depois dessas primeiras experiências de AJUP, núcleos diversos foram surgindo em todo o país. 


\section{Assessoria jurídica universitária no estado do Ceará}

No site da RENAJU há um mapeamento de AJUPs, AJPs e movimentos sociais que atuam na mesma linha, contendo 37 núcleos. Já Fabiana Cristina Severi (2014, p. 23) buscou mapear e analisar as experiências de AJUPs brasileiras, identificando 42 núcleos no Brasil. Contudo, esta pesquisa levantou apenas os núcleos no Estado do Ceará, identificando 6 AJUPs, dentre as quais 1 foi desativada durante o desenvolvimento da pesquisa. Além disso, foram mapeados 2 escritórios de advocacia popular (Quadro 1).

Quadro 1 - Mapeamento das assessorias jurídicas universitárias populares no Ceará

\begin{tabular}{|c|c|c|}
\hline Nome do núcleo & Universidade/cidade & Tempo de atuação \\
\hline $\begin{array}{l}\text { Centro de Assessoria Jurídica } \\
\text { Universitária (CAJU) }\end{array}$ & $\begin{array}{l}\text { Universidade Federal do } \\
\text { Ceará (UFC) - Fortaleza }\end{array}$ & 21 anos \\
\hline $\begin{array}{l}\text { Núcleo de Assessoria Jurídica } \\
\text { Comunitária (NAJUC) }\end{array}$ & UFC - Fortaleza & 26 anos \\
\hline $\begin{array}{l}\text { Serviço de Assessoria Jurídica } \\
\text { Universitária Popular (SAJUP) }\end{array}$ & $\begin{array}{l}\text { Universidade de Fortaleza } \\
\text { (Unifor) - Fortaleza }\end{array}$ & 19 anos \\
\hline $\begin{array}{l}\text { Coletivo de Assessoria Jurídica } \\
\text { Universitária Popular (CAJUP SITIÁ) }\end{array}$ & $\begin{array}{l}\text { Centro Universitário Católica } \\
\text { de Quixadá (Unicatólica } \\
\text { Quixadá) - Quixadá }\end{array}$ & 3 anos \\
\hline AJUP MARIA TOMÁSIA & $\begin{array}{l}\text { Universidade Estadual Vale do } \\
\text { Acaraú (UVA) - Sobral }\end{array}$ & $\begin{array}{l}2 \text { anos e } 5 \text { meses } \\
\text { (desativada) }\end{array}$ \\
\hline $\begin{array}{l}\text { Programa de Assessoria Jurídica } \\
\text { Estudantil (P@JE) }\end{array}$ & $\begin{array}{l}\text { Universidade Regional do } \\
\text { Cariri (URCA) - Crato }\end{array}$ & 13 anos \\
\hline
\end{tabular}

Fonte: Elaborada pelos autores.

Além dos grupos de AJUP existem 2 escritórios de advocacia popular em Fortaleza: a) o Escritório de Direitos Humanos e Assessoria Jurídica Popular Frei Tito de Alencar; e b) o Escritório Dom Aluísio Lorscheider. Estes, inclusive, realizam atividades em parceria com os núcleos de AJUP de Fortaleza, o que justifica contemplá-los neste estudo. 
Cada grupo investigado atua em uma área diferente. O Núcleo de Assessoria Jurídica Comunitária (NAJUC), concebido no curso de Direito da Universidade Federal do Ceará (UFC), em Fortaleza, tem 26 anos de existência e conta com 9 membros. Sempre atuou na defesa dos direitos humanos e já fez várias articulações junto aos movimentos sociais na busca da garantia de moradia digna nas comunidades da capital do estado. Também já atuou na área carcerária, em especial no âmbito socioeducativo, produzindo oficinas e relatórios tanto em comunidades como com sujeitos em conflito com a lei.

Dentro da universidade, o NAJUC promove eventos sobre as temáticas gênero, sexualidade, negritude, direito à moradia, direitos humanos, entre outras pouco debatidas e aprofundadas no meio acadêmico. Atualmente, luta pela concretização das Zonas Especiais de Interesse Social (ZEIS), em Fortaleza, instrumento usado nos planos diretores municipais para sua melhor estruturação, efetivando as funções sociais da cidade e da propriedade urbana, promovendo a regularização urbanística e fundiária dos assentamentos que abrigam as famílias de baixa renda, eliminando os riscos das ocupações em áreas inadequadas e ampliando a oferta de infraestrutura urbana e de equipamentos comunitários - o que promove a qualidade ambiental junto aos seus moradores.

Entretanto, embora seja o grupo mais antigo do Ceará, o NAJUC afirma passar por grandes dificuldades. A instituição de ensino não financia suas atividades, sendo a falta de recursos um dos principais obstáculos para o melhor desenvolvimento de suas atividades.

Além do NAJUC, na UFC também há o Centro de Assessoria Jurídica Universitária (CAJU), com 21 anos de existência e 14 membros ativos. Sobre suas atividades mais atuais, afirma acompanhar a Frente de Luta por Moradia Digna desde 2015, bem como o Conselho Gestor da ZEIS Lagamar; em 2016 iniciou um projeto que desenvolve formação em escolas públicas estaduais e em ocupações urbanas - entre elas a do Movimento dos Trabalhadores Sem Teto (MTST) - sobre acesso à Justiça e direito à cidade, além de realizar eventos periódicos na Faculdade de Direito, como o Cine Calouro e os Diálogos Críticos, no início de cada semestre, entre outros.

Já o Serviço de Assessoria Jurídica Universitária Popular (SAJUP), da Universidade de Fortaleza (Unifor), instituição privada, conta 19 anos de atividade, demonstrando-se tão resistente quanto os outros, haja vista as instituições de Ensino Superior (IES) privadas serem ainda mais fechadas à promoção de atividades que contemplem ideias alternativas no âmbito jurídico. Inicialmente, sua atuação se deu junto às comunidades Pau Finim e Titanzinho, em defesa do direito à moradia e do acesso à Justiça. Também acompanhou a ocupação urbana Squat Toren, em Fortaleza, e as atividades de luta pelas ZEIS e o Comitê Popular da Copa. E atuou junto a comunidades de Fortaleza atingidas pelas obras do Veículo Leve sobre Trilhos (VLT).

O Programa de Assessoria Jurídica Estudantil (P@JE) tem 13 anos de existência e conta com 25 membros ativos. No questionário, relatou-se que o P@JE já realizou atividades 
de extensão universitária com detentos na cadeia pública do Município do Crato-CE, com o grupo de jovens do Assentamento 10 de Abril, que integra o Movimento dos Trabalhadores Rurais Sem Terra (MST), com jovens em conflito com a lei no Centro de Semiliberdade de Juazeiro do Norte-CE e com alunos do Ensino Médio de escolas públicas estaduais da Região do Cariri. Na universidade, também realiza eventos sobre temas relacionados aos direitos humanos e ao combate às opressões relacionadas a gênero, raça e orientação sexual. Busca, constantemente, firmar parcerias com os movimentos sociais, sempre participando das manifestações e pautas de lutas regionais.

O Coletivo de Assessoria Jurídica Universitária Popular (CAJUP SITIÁ), do Centro Universitário Católica de Quixadá (Unicatólica Quixadá), instituição privada, conta apenas 3 anos de existência e tem 6 membros. Relatou no questionário que sua principal conquista se deu na luta em conjunto com as comunidades Cafundó e Escondidos para obter 26 cisternas, com vistas a ter acesso a água potável. Apesar de já ter sido bem ativo na universidade e nas comunidades da cidade, o que gerou grande reconhecimento de sua importância dentro da IES, ao sempre discutir temas relacionados aos direitos humanos. Contudo, seus membros confessam que estão passando por uma crise desde o último semestre do ano 2018, o que inviabilizou a continuação de suas atividades nas comunidades, mas que seguem se organizando dentro da IES.

Em Sobral-CE, existiu na Universidade Estadual Vale do Acaraú (UVA), até meados do ano 2018, a AJUP Maria Tomásia - que quase chegou aos 3 anos de duração. O grupo informou chegar a realizar atividades em escolas públicas do município e eventos na universidade, como rodas de conversa sobre extensão universitária popular, direitos humanos, questões de raça e gênero. Contudo, a falta de apoio da IES dificultou a realização de tais atividades e, por consequência, inviabilizou a própria sobrevivência do grupo.

Após compreenderem o teor da pesquisa e concordarem em participar do estudo de forma voluntária, os integrantes dos grupos responderam o questionário sobre as motivações que os levaram a participar das AJUPs.

Integrantes do NAJUC afirmaram:

Tenho necessidade de ver o direito não sendo usado para legitimar a classe dominante, mesmo sabendo de suas próprias limitações. (Ítalo, 23 anos) Sempre me identifiquei com pautas sociais, e a AJP incitava essas discussões, além da vontade de fazer um curso diferente daquele que é proposto pela faculdade, saindo da universidade e tendo uma visão diferente do mundo e do direito. (Isabella, 20 anos)

Integrantes do SAJUP se disseram motivados pela "afinidade com pautas sociais e a crítica ao direito tradicional" (Wesley, 21 anos) e pela "criticidade do direito aprendido na 
academia, participação em movimentos sociais, efetiva mudança social”' (Fabiana, 19 anos). Integrantes do P@JE indicaram:

O interesse em fazer a diferença e ajudar as pessoas, adorei a proposta do meu grupo e quis fazer parte da causa. (Dandara, 19 anos) A abordagem dos temas relativos a direitos humanos, a possibilidade de integrar um movimento de assessoria jurídica popular, extensionista e que colabora de maneira horizontal com a sociedade e entre si. (Raquel, 22 anos)

E integrantes do CAJU relataram:

A minha indignação com a passividade e com a banalização de muitas pessoas ao meu redor, tanto na universidade quanto fora dela, em relação às constantes violações de direitos que acontecem cotidianamente, principalmente em Fortaleza; a vontade de contribuir para a efetivação do direito àqueles que mais enfrentam dificuldades para ter suas garantias básicas asseguradas e a percepção do direito como uma ferramenta que deve estar a serviço prioritariamente dessas pessoas que se veem marginalizadas por um sistema que Ihes deveria proporcionar dignidade. Para além dessas coisas, algo que me fez acreditar mais nas causas sociais foi ter participado dos Diálogos Críticos, rodas de discussão sobre temas que perpassam as atuações do grupo todo início de semestre, realizadas pelo CAJU-UFC, em meu primeiro semestre na Universidade. (Natália, 19 anos) A perspectiva social que a assessoria jurídica traz para a prática do direito, tradicionalmente aliada a um pensamento elitista e afastado das populações mais marginalizadas. A prática da AJUP mudou tanto a concepção que eu tinha sobre o Direito, até então um curso que não me deixava confortável, quanto a visão de universidade e de mundo que eu tinha. Estar atuando junto de comunidades, lutando pela justiça social, reafirmando o compromisso diário com as populações vulneráveis me faz acreditar cada dia que a luta vale a pena e que cada conquista nessa atuação pequena faz a diferença na vida de centenas de pessoas. (Vitória, 19 anos)

Dentre os investigados, a maioria respondeu que almeja seguir profissionalmente na Defensoria Pública e na advocacia popular. Além disso, respostas como necessidade e vontade de militar, concordância com as causas e bandeiras defendidas e busca por novos temas dentro do Direito demonstram que participar desses grupos induz os acadêmicos a despertar para a participação ativa na luta pela garantia e proteção dos direitos humanos e da transformação social. Uma influência que não se mostra possível dentro dos parâmetros tradicionais do curso de Direito em sala de aula. 


\section{Considerações finais}

A noção mais ampla do que é educação, a qual difere do ensino e da instrução, possibilita uma nova concepção de práticas, saberes e aprendizagem. A AJUP, tendo por base teórica a educação popular em direitos humanos, assume papel de suma relevância dentro da faculdade de Direito ao buscar a coexistência, pensar novas epistemologias, discutir lugares sociais e romper com a visão única, majoritariamente positivista, imposta na área jurídica.

Leva-se em consideração que o conhecimento enclausurado e limitado às salas de aula e à letra de lei não é eficaz. A preocupação com a sociedade nos núcleos da AJUP, bem como sua permanente formação política a partir da criticidade do direito, sua atuação junto aos movimentos sociais e sua participação ativa nas disputas travadas no contexto da divisão e luta de classes, demonstra por si a contribuição para a formação educacional, profissional e humana do assessor popular.

Este estudo descreveu o papel exercido pela AJUP dentro das IES, que possibilita aos cursos de Bacharelado em Direito refletir sobre sua habilitação, seus métodos e seus materiais pedagógicos, integrando as práticas de pesquisa e extensão, em busca da construção de um espaço universitário mais democrático e da formação de operadores do direito engajados em lutas sociais.

\section{Referências bibliográficas}

Almeida, A. L. V. (2015). Um estalo nas faculdades de direito: perspectivas ideológicas da assessoria jurídica universitária popular (Tese de Doutorado). Universidade Federal da Paraíba, João Pessoa, PB.

Andrade, G. L. (2009). Ensino jurídico no Brasil? Brevíssimas anotações: do legado liberal à encruzilhada pós-moderna. Recuperado de https://www.webartigos.com/artigos/ensino-juridico-no-brasil-brevissimas-anotacoes-do-legado-liberal-a-encruzilhada-pos-moderna/29947\#ixzz5Kr9XImAQ Andrade, L.R. (1996). Introdução ao direito alternativo brasileiro. Livro do Advogado; Florianópolis: Unisul.

Bove, L. A. (2006). Uma visão histórica sobre o ensino jurídico no Brasil. Revista da Faculdade de Direito, 3(3), 115-138.

Constituição da República Federativa do Brasil, de 5 de outubro de 1988. (1988). Brasília, DF.

Fagúndez, P. R. Á. (1997). A crise do ensino jurídico. Recuperado de http://blog.newtonpaiva.br/ direito/wp-content/uploads/2012/08/PDF-D3-02.pdf

Machado, A.A. (2009). O direito alternativo. Recuperado de https://avessoedireito.wordpress. com/2009/09/24/o-direito-alternativo/ 
Freire, P. (2005). Pedagogia do Oprimido (42 ed). Rio de Janeiro: Paz e terra.

Linhares, M. T. M. (2009). Educação, currículo e diretrizes curriculares do curso de direito: um estudo de caso (Tese de Doutorado). Pontifícia Universidade Católica de São Paulo, São Paulo, SP.

Severi, F. C. (2014). Cartografia social e análise das experiências de assessorias jurídicas universitárias populares brasileiras (Relatório de Pesquisa). Ribeirão Preto, SP: Universidade de São Paulo.

\section{Para citar este artigo:}

\section{Norma A - ABNT}

SILVA, L. M. N.; SOUSA, A. O.; ACIPRESTE SOBRINHO, D. F. Direito e resistência: grupos de assessoria jurídica universitária popular no Ceará. Conhecer: Debate entre o Público e o Privado, n. 22, p. 188-201, 2019.

\section{Norma B - APA}

Silva, L. M. N., Sousa, A. O., \& Acipreste, D. F., Sobrinho. (2019). Direito e resistência: grupos de assessoria jurídica universitária popular no Ceará. Conhecer: Debate entre o Público e o Privado, 2019(22), 188-201.

\section{Norma C - Vancouver}

Silva LMN, Sousa AO, Acipreste Sobrinho DF. Direito e resistência: grupos de assessoria jurídica universitária popular no Ceará. Conhecer: Debate entre o Público e o Privado [Internet]. 2019 [cited Abr 22, 2019];(22):188-201. Available from: https://revistas.uece.br/index.php/revistaconhecer/ article/view/1033 